\title{
História da construção do Código de Ética Profissional do Psicólogo
}

\section{The history of the Code of Ethics for the Psychologist \\ La historia del Código de Ética Profesional para Psicólogo}

\author{
Marcia Ferreira Amendola* \\ Hospital Universitário Pedro Ernesto - HUPE, Rio de Janeiro, Rio de Janeiro, Brasil
}

\begin{abstract}
RESUMO
A história da construção do Código de Ética profissional do Psicólogo, narrada neste texto, articula os elementos do passado com a percepção da autora sobre os mesmos, sua análise e forma de descrevê-los, sem a pretensão de preencher vazios deixados pela História Oficial. Porém, contribuir para lançar luz a uma das mais respeitáveis conquistas da Psicologia após sua regulamentação: a construção do seu código de conduta. O texto traz uma visão sobre o sentido de um código de conduta tanto para o profissional quanto para a sociedade e, posteriormente, apresenta dados históricos contextualizados sobre origem dos quatro Códigos de Ética Profissional do Psicólogo (CEPP) e demais Resoluções do Conselho Federal de Psicologia a eles relacionadas. Ao final, faz-se uma análise crítica sobre o atual CEPP e um apontamento sobre o caráter referencial deste, de modo que os profissionais psicólogos devem considerar, além do CEPP, os valores e princípios nutridos ao longo de sua formação pessoal e profissional.

Palavras chave: história da psicologia, ética, código de ética.
\end{abstract}

\section{ABSTRACT}

The story of the Code of Ethics for the Psychologist told in this paper articulates the elements of the past with the perception of the author about them, her analysis and form of narrating them, without pretending to fill voids left by the Official History. However, contribute to shed light to one of the most respectable achievements of psychology after its regulation: the construction of its code of conduct. The text provides an insight into the meaning of a code of conduct for both the professional as to society and then displays contextualized historical data on origin of the four Code of Ethics for the Psychologist (CEPP) and other Resolutions of the Federal Council of Psychology related to them. Finally, the author makes a critical analysis of the current CEPP and a note about the referential character, so that professional psychologists should consider, besides the CEPP, values nurtured throughout his personal and professional development.

Keywords: history of psychology, ethics, code of ethics.

\section{RESÚMEN}

La historia del Código de Ética Profesional para Psicólogo que se cuenta en este manuscrito articula los elementos del pasado con la percepción de la 
autora acerca de ellos, su análisis y la forma de describir que, sin pretender llenar los vacíos dejados por la historia oficial. Sin embargo, contribuyen a arrojar luz a uno de los más respetables logros de la psicología después de su regulación: la construcción de su código de conducta. El texto ofrece una visión del significado de un código de conducta, tanto para el profesional como para la sociedad y luego presenta datos históricos contextualizados sobre el origen de los cuatro del Código de Ética Profesional del Psicólogo (CEPP) y otras resoluciones del Consejo Federal de Psicología relacionado con ellos. Por último, se realiza un análisis crítico del CEPP actual y una nota sobre el carácter referencial este, por lo que los psicólogos profesionales deben considerar, a más de del CEPP, valores y principios nutrido a través de sus de desarrollo personal y profesional.

Palabras clave: historia de la psicología, la ética, el código de ética

\section{Introdução}

Pois não somos tocados por um sopro do ar que foi respirado antes? Não existem, nas vozes que escutamos, ecos das vozes que emudeceram?

(...) Se é assim, existe um encontro marcado entre as gerações precedentes e a nossa.

Walter Benjamin

A única coisa que devemos à história é a tarefa de reescrevê-la Oscar Wilde

Aqueles que se preocupam com o resgate da história voltam os olhares para os acontecimentos do passado, percebendo que nada se perde no esquecimento; todos os acontecimentos são relevantes. Impossível, porém, recobrar o passado em sua exatidão, uma vez que história é discurso, é construção que decorre da seleção, dos recortes, do entendimento e do modo de narrar do historiador. Assim, história é reinvenção do passado no presente, quando os elementos do passado encontram ressonância nos acontecimentos de hoje (Matter, n.d.).

Igualmente, narrar uma história não significa, necessariamente, contar a verdade, pois, como diz Walter Benjamin (1989):

(...) a narração não tem a pretensão de transmitir um acontecimento, pura e simplesmente (como a informação o faz); Integra-o à vida do narrador, para passá-los aos ouvintes como experiência. Nela ficam impressas as marcas do narrador como os vestígios das mãos do oleiro no vaso de argila (p.107).

Para tanto, fez-se, além de revisão da literatura, pesquisa no acervo bibliográfico do Clio-Psyché - Programa do Departamento de Psicologia Social e Institucional do Instituto de Psicologia da UERJ - e 
junto ao Conselho Federal de Psicologia (CFP), requerendo textos sobre as normativas da categoria, em especial, as Resoluções que instituíram os quatro Códigos de Ética da profissão.

O trabalho de pesquisa que originou este artigo integrou a tese de doutorado da autora que se propunha a discutir o agir ético do profissional psicólogo. Dessa forma, surgiu a ideia de conhecer a história da construção dos Códigos de Ética, fato que gerou certa perplexidade diante da carência de registros sobre determinados acontecimentos que compõem a origem da própria profissão de Psicologia.

Com efeito, a história aqui narrada articula os elementos do passado, na forma de documentos, normativas e depoimentos, com a percepção da autora sobre os mesmos, sua análise e forma de descrevê-los, sem a pretensão de preencher vazios deixados pela História Oficial, porém, contribuir para lançar luz a uma das mais respeitáveis conquistas da Psicologia após sua regulamentação enquanto ciência e profissão: a construção do seu código de conduta. Um Código de conduta tem por finalidade apresentar os princípios que determinado grupo de pessoas deverá utilizar como referência para suas ações. Inversamente, estes mesmos princípios também servirão como recurso para avaliar e julgar as ações desse grupo em relação à sociedade (se tais ações estão ou não em conformidade com o Código).

Por se tratar de um instrumento que visa a dar indicações a uma determinada prática, existe uma enormidade de Códigos, dentre os quais, aquele direcionado ao exercício profissional, conhecido por Código Deontológico ou Código dos deveres (deon) profissionais. Habitualmente denominado de Código de Ética Profissional, um Código Deontológico se refere a um código de conduta, cuja função consiste em fornecer elementos para moldar, regulamentar as relações entre os profissionais e entre estes e a sociedade, com vistas à harmonia de uma ordem social (Benavides \& Antón, 1987).

Nesse sentido, o Código de Ética apresenta-se como um coadjuvante na construção da identidade profissional, de uma concepção de pertencimento, ao mesmo tempo em que dá legitimidade à profissão perante a sociedade.

A ideia de uma comunidade de integração é uma noção herdada da hoje ancestral era do pan-óptico: ela se refere ao esforço organizado de fortalecer a fronteira que separa o "interior" do "exterior", de manter os internos dentro, enquanto se impede os outsiders de entrarem e os próprios internos de praticarem desvios, quebrando normas e planejando escapar do pulso da rotina. Tudo isso diz respeito à execução de um código de conduta uniforme, monotônico, imputado em termos de espaço e tempo (Bauman, 2011, p.27-28). 
Este processo, todavia, não se dá sem embates e contradições próprios das disputas e interesses político-econômicos e ideológicos na sociedade. Tal fato remete à compreensão de que todo Código não está isento da ideologia daqueles que representam o sistema do poder, como lembra Benavides e Antón (1987):

Segundo estes ideólogos [Marx, Nietzsche e Freud], os códigos morais se criam como sendo reflexos de "interesses das classes dominantes" e "expressão do poder" (Marx); como "sanção do vulgo e dos débeis tolhidos para prevalecer sobre os fortes e nobres" (Nietzsche); ou como ideal "paterno opressor dos instintos" (Freud). Em todo caso, são entendidas as normas como "algo exterior" que leva a estabelecer um estado de coisas, que se bem pode ser benéfico com vistas a criar certa ordem pacífica e rendosa (Benavides e Antón, 1987, p.52).

Por este motivo, todo Código, que não seja uma Lei no sentido estrito e, portanto, possa ser mais sensível ao contexto econômico-político e cultural de uma dada sociedade, tem um aspecto dinâmico, o que permite - à medida que a sociedade e a própria profissão se movimentam -, a revisão, transformação, renovação e reedição de seus artigos para se aproximarem aos novos costumes (Pegoraro, 2005).

No caso do Código de Ética Profissional do Psicólogo (CEPP), trata-se de uma norma jurídica, cuja denominação técnica é Resolução. Enquanto tal, possui caráter normativo e regulador da profissão. A partir desse instrumento jurídico, o Conselho Federal de Psicologia (CFP) institui, por escrito, o dever-ser da conduta moral do profissional da Psicologia.

Não obstante a controvérsia que possa suscitar e a lacuna que possa haver, o CEPP é "uma norma imperativa, oponível a toda categoria dos psicólogos no Brasil e com força coercitiva e de sanção" (Pereira, 1991, p.33). Em outras palavras: trata-se de um sistema de regras que visa à regulação da conduta profissional do psicólogo, apontando responsabilidades, direitos e deveres, de caráter obrigatório e coercitivo, de tal modo que seu descumprimento é passível de punição.

Bock (2008), quando ainda exercia a função de conselheirapresidente do XIII Plenário do CFP, declarou, em palestra transcrita no livro Profissão Psicólogo, que a função do Código de Ética Profissional do Psicólogo é orientar a atividade do psicólogo, devendo ser encarado como um acordo de regras de conduta profissional.

Esclarece-se que é importante não absolutizar o Código de Ética, pois pode haver interpretações diversas sobre as regras 
que estão postas, aliás, é por este motivo que existe o julgamento, porque, se fosse absolutamente claro, não haveria a necessidade de se julgar, era só aplicar as regras. É necessária a ideia de se ter o Código como um orientador para se debaterem questões referentes à ética profissional, à infração ao Código, ao tipo de conduta de infração que tem sido encontrada, entre outros aspectos (Bock, 2008, p.101).

Inequivocamente, uma categoria profissional, para ter seu campo institucionalizado e reconhecido pela sociedade, é obrigada a manter um Código de conduta para proteção e defesa dos direitos dos usuários de seus serviços profissionais, sejam estes seus clientes ou instituições.

Desta forma, este [o Conselho Regional de Psicologia] é um lugar que recebe denúncias de pessoas que são usuárias dos serviços dos psicólogos, e é a serviço delas que o Conselho trabalha, não ao contrário. O Conselho não existe para defender os psicólogos das pessoas que vêm apresentar denúncia, e essa perspectiva faz a diferença no trato com a pessoa que vem apresentar a sua denúncia, ou na forma como a denúncia é acolhida (Bock, 2008, p.100).

Além do Código de Ética estar atento para as demandas da sociedade, como afirmou a autora, entende-se, por sua vez, que ele também tem por função orientar e proteger o próprio profissional. Este entendimento não compromete, em absoluto, a fala da então presidente do CFP, pois não é função do Conselho de Classe defender o psicólogo, enquanto indivíduo, quando este é denunciado ou em qualquer circunstância, seja Ihe oferecendo assistência jurídica, seja deixando de receber denúncias, etc. Sua função é executiva e voltada para a defesa da integridade da Psicologia enquanto profissão perante a sociedade.

Todavia, entende-se que igualmente é função do CFP elaborar um Código de Ética que corresponda às necessidades da categoria e divulgá-lo para que o profissional possa, ao conhecê-lo, usá-lo como um referencial a ser observado com vistas a tomar suas decisões frente aos desafios da profissão. Porém, não basta que o Conselho Federal de Psicologia construa um Código e o divulgue para que a categoria o cumpra. É forçoso que, ao oferecê-lo, também instrumentalize, ou seja, dê condições para que o profissional consiga articular as normas com sua prática de um modo coerente e criativo, já que é a ele que o Código de Ética é endereçado e sobre ele que incidem as denúncias de infração. 


\section{Primeiro código de ética dos psicólogos brasileiros}

Para responder às exigências da população, as quais envolvem questões de ética profissional, assim como pontos de referências para a orientação e fiscalização no Brasil, enfim, para controlar o exercício da profissão, os "interesses cristalizados ideologicamente" (Aguiar, 1984, p.69) deveriam ser instrumentalizados em normas. Foi quando uma espécie de primórdio do Código de Ética - o designado Código de Ética dos Psicólogos Brasileiros, foi organizado no biênio 1966-67. Nestes termos, a Psicologia passou a ter sua deontologia, ou seja, um mecanismo contra os que ilegalmente exercerem a profissão, bem como "uma ciência disciplinadora e disciplinada" (Aguiar, 1984, p.69), capaz de controlar os profissionais por meio de normas, sanções, e, principalmente, "se colocar sempre como tutor dos interesses da coletividade" (Aguiar, 1984, p.72).

Importante destacar que o Conselho Federal de Psicologia (CFP), criado posteriormente pela Lei $n^{\circ} 5.776$ de 1971, com a função, entre outras, de regulamentar a profissão do Psicólogo, com a obrigatoriedade de exercer função normativa e baixar atos à execução da legislação reguladora do exercício profissional, objetivou a elaboração e consequente aprovação do Código de Ética Profissional do Psicólogo brasileiro. Tratava-se, anteriormente, de um anteprojeto do Código da Ética Profissional, o qual foi elaborado a partir de discussões promovidas pela Associação Brasileira de Psicólogos (ABP), fundada em 1954, então presidida por Arrigo Angelini, e a Sociedade de Psicologia de São Paulo (SPSP), que congregavam psicólogos de várias agremiações. Durante os encontros na Sociedade Brasileira para o Progresso da Ciência (SBPC), este Código tinha o propósito de refletir as necessidades da Psicologia na ocasião.

O documento original foi proposto por Oswaldo de Barros Santos, associado de ambas as entidades, e se referia a um conjunto de normas de ética profissional para psicólogos publicado pela New York State Psychological Association. O texto foi traduzido e adaptado para o Brasil por Betty Katzenstein e Eliezer Schneider e posteriormente publicado nos Arquivos Brasileiros de Psicologia Aplicada.

Weil (1967) dá maiores detalhes:

Cópias do referido anteprojeto foram distribuídas à Sociedade de Psicologia do Rio Grande do Sul, à Sociedade Mineira de Psicologia e a diversos serviços de aplicação da Psicologia, e Faculdades de Filosofia. Em seguida, foi o anteprojeto submetido a uma ampla discussão que teve lugar em Ribeirão Preto, em julho de 1964, quando da realização de uma assembleia geral da ABP, por ocasião da XVI Reunião Anual da Sociedade Brasileira para o Progresso da Ciência. Em consequência, numerosas sugestões foram feitas, ou enviadas 
por escrito, e para estudar a conveniência ou não da inclusão das alterações propostas, foi nomeada uma comissão integrada pelos profs. Drs. Arrigo L. Angelini, Pedro Parafita de Bessa, Arthur M. Saldanha, Dante M. Leite, Pé. Antonius Benko, Enzo Azzi e Prof. Osvaldo de Barros Santos. Por dificuldades diversas, inerentes a uma Comissão, cujos componentes se encontravam em pontos diferentes do país, não houve oportunidade de um trabalho em conjunto. No entanto, isoladamente, cada membro dessa Comissão, que havia recebido cópia de todo o material resultante da Assembleia Geral realizada em Ribeirão Preto, examinou o referido material à luz do anteprojeto original. Em julho de 1965, na Assembleia Geral de ABP, realizada em Belo Horizonte, por ocasião da XVII Reunião Anual da Sociedade Brasileira para o Progresso da Ciência, voltou-se a discutir o novo anteprojeto, cujos pontos principais foram apresentados e aprovados nessa Assembleia Geral da Associação Brasileira de Psicólogos pelos relatores da Comissão anteriormente indicada em Ribeirão Preto - Drs. Pedro Parafita de Bessa e Arthur $M$. Saldanha que também cuidaram da redação final do novo anteprojeto. Ampla divulgação desse anteprojeto foi feita pela A. B. P. entre seus associados. Finalmente, na Assembleia Geral da A. B. P. realizada em Blumenau, por ocasião da XVIII Reunião Anual da S. B. P. C. aos 12 dias do mês de julho de 1966 o novo anteprojeto foi unanimemente considerado O CÓDIGO DE ÉTICA DOS PSICÓLOGOS BRASILEIROS e decidiu-se recomendar a adoção do mesmo por todos quantos se dedicam profissionalmente à Psicologia em nosso meio (Weil, 1967, p.258-259).

Conforme Weil (1967) menciona em seu texto, foi por determinação do Código de Ética dos Psicólogos Brasileiros que a Assembleia Geral da Associação Brasileira de Psicologia (ABP), realizada em Blumenau no ano de 1966, nomeou os membros do Conselho de Ética Profissional, entidade que se incumbiria de orientar a aplicação deste Código de Ética, zelar pela sua observância e fiscalizar o exercício profissional.

Para tanto, seria imprescindível uma normativa na qual os membros desse Conselho de Ética pudessem se orientar na apuração das faltas disciplinares e infrações ao Código de Ética. Porém, um ano antes que essa normativa - conhecida por Código de Processamento Disciplinar (CPD) -, Resolução CFP $n^{\circ}$ 014/1976, fosse instituída, a Psicologia já dispunha de outro instrumento legal elaborado a partir do anteprojeto Código de Ética dos Psicólogos Brasileiros, oficialmente batizado como o primeiro Código de Ética Profissional do Psicólogo (CEPP) - 
Resolução CFP $\mathrm{n}^{\circ}$ 8, de 02 de fevereiro de 1975 -, publicada no Diário Oficial da União.

O primeiro Código de Ética da categoria era composto por cinco Princípios Fundamentais e 40 (quarenta) artigos, distribuídos em 13 (treze) capítulos: das responsabilidades gerais do psicólogo; das responsabilidades para com o cliente; das responsabilidades e relações com as instituições empregadoras; das relações com outros psicólogos; das relações com outros profissionais; das relações com associações congêneres e representativas do psicólogo; das relações com a justiça; do sigilo profissional; das comunicações científicas e das publicações; da publicidade profissional; dos honorários profissionais; da fiscalização do exercício profissional da psicologia e cumprimentos dos princípios éticos; disposições gerais.

Conforme explica Mello (1983), o CEPP, pelo conteúdo ideológico que apresentava, parecia ter sido extraído de códigos médicos. "As pretensões implícitas seriam as de reivindicar para a profissão recémnascida, as prerrogativas e o prestigio da profissão médica" (p.104). Se a Psicologia não é a Medicina, a autora questiona se não seria mais interessante para a profissão definir sua própria problemática ética. Entende, ainda, que neste instrumento, há o reconhecimento da necessidade do profissional "desenvolver o sentido de sua responsabilidade" (p.104), a partir do aprimoramento de seus conhecimentos. Concorre que, na ausência de um consenso em relação aos princípios expostos no Código, ficaria a critério de cada profissional a interpretação dos mesmos.

\section{Segundo código de ética profissional dos psicólogos}

Passados quatro anos do Código de Ética de 1975, o número de profissionais psicólogos no país mais que quadruplicou, atingindo o equivalente a 20 mil profissionais registrados, a maioria ligada a atividades liberais, privativas, de cunho clínico-curativo/terapêutica. Essa acelerada expansão, assim como as constantes transformações da sociedade fizeram-se acompanhar de um desequilíbrio frente a algumas áreas de atuação profissional, de tal modo que a Gestão do CFP entendeu ser necessário manter as discussões em torno do Código (Velloso, 1980).

A emergência de novos campos de atividades também contribuiu para o entendimento do CFP sobre a necessidade de realizar uma revisão do Código - já prevista em seu artigo $1^{\circ}$, tarefa atribuída ao Conselho de Ética do CFP. Os trabalhos tiveram início em 1978, culminando com a aprovação da nova versão do Código em 30 de agosto de 1979, por ocasião da comemoração do centenário da Psicologia, sob a forma de Resolução CFP $n^{\circ}$ 029/79 (Conselho Regional de Psicologia 06 [CRP 06], 1994). 
O Conselho de Ética do CFP também analisou 13 Códigos de Éticas de outras profissões (Serviço Social, Odontologia, Medicina, etc.) em busca de elementos compatíveis com o exercício profissional do psicólogo. Com base nesses dados, juntamente com os demais, o Conselho de Ética elaborou uma minuta do Código de Ética que foi remetida aos Conselhos Regionais de Psicologia (CRPs) para nova apreciação.

Velloso (1980) descreve, sucintamente, como se desenvolveu o trabalho de reformulação do Código: primeiramente, os Conselhos Regionais deveriam realizar críticas ao Código de 1975 e dar sugestões para sua reformulação, tomando por base os trabalhos desenvolvidos no campo da fiscalização e da orientação. Posteriormente, os CRPs encaminharam aos professores de ética dos cursos de Psicologia fornecidos pelo Ministério da Educação e Cultura mesmo pedido endereçado aos CRPs (críticas e sugestões em relação ao Código). Foi também realizado um levantamento pela Biblioteca da Universidade de São Paulo de revistas estrangeiras de verbetes sobre ética profissional do psicólogo, material que foi encaminhado a todos os conselheiros.

Findo o prazo de 30 dias para essa etapa, a Comissão procedeu a uma nova discussão e elaboração de uma segunda minuta, que foi apresentada ao Plenário do CFP para reformulação, votação e aprovação do Código (Velloso, 1980).

O CEPP de 1979 entrava em vigor, ainda no período político ditatorial, porém, em um momento em que os movimentos sociais de resistência se fortaleciam. Apresentando cinco Princípios Fundamentais e 50 artigos e mais alíneas dispostos em 12 capítulos, é possível constatar que alguns temas ganharam ênfase, tais como os que versavam sobre sigilo e relações com a Justiça, enquanto outros foram excluídos, tal como a alínea ' $h$ ' do Art. $4^{\circ}$ do Código anterior, que versa sobre a prática de interrogatório sob ação de hipnose (Romaro, 2008). Assim, o segundo Código passou a ter por capítulos: das responsabilidades gerais do psicólogo; das responsabilidades para com o cliente; das responsabilidades e relações com as instituições empregadoras; das relações com outros psicólogos; das relações com outros profissionais; das relações com associações congregantes e representantes dos psicólogos; das relações com a justiça; do sigilo profissional; das comunicações científicas e da divulgação ao público; da publicidade profissional; dos honorários profissionais; da observância, aplicação e cumprimento do Código de Ética.

Para Drawin (1985), este segundo Código de Ética Profissional apresentava-se fortemente marcado "pelo ranço corporativista" (p.16). Segundo o autor, a estrutura do código seria simples, com artigos em duas direções paralelas: "a preservação da dignidade do cliente e a preservação da dignidade do próprio profissional, para 
concluir na consolidação da imagem social do psicólogo, que deve assegurar a integralidade do mercado de trabalho" (Drawin, 1985, p.16).

Concomitante aos trabalhos de organização e aprovação do CEPP de 1979, houve a aprovação da Resolução CFP $n^{\circ}$ 001/1978 que estabeleceu, em caráter permanente, uma Comissão de Fiscalização do Exercício profissional. Com isso, a Comissão de Ética (Coe) - que antes cumulava a função de zelar pela ética profissional e fiscalizar o exercício profissional - passou a se dedicar à disciplina, via instauração, instrução (condução) e julgamento de Processos Disciplinares Éticos (PDE) representados em desfavor dos psicólogos, dentro do rigor da Lei. Desta forma, a Comissão de Ética (Coe) operaria, dentro dos CRPs, como um órgão de assessoria ao Plenário que atuaria como um Tribunal Regional de Ética, enquanto o CFP operaria como um Tribunal Superior de Ética Profissional.

Para normatizar o trabalho das Comissões de Ética na instrução dos processos disciplinares propostos contra o psicólogo em todo o país, foi instituído, no ano de 1982, um novo Código de Processamento Disciplinar (CPD), Resolução CFP n 015/1982. No ano seguinte, nova Resolução foi emitida em substituição a esta, entrando em vigor a Resolução CFP n 009/1983.

\section{Terceiro código de ética profissional do psicólogo}

Mudanças na conjuntura política e socioeconômica despontavam no horizonte do país da década de 1980 , quando a população sofria com o empobrecimento, crescimento desordenado e concentração nos centros urbanos, associado ao processo de abertura democrática e ao movimento para eleições diretas para presidente (1984) - Diretas Já. Na medida em que a sociedade brasileira se democratizava, criavase, segundo Oliveira (2005), uma possibilidade para a expressão da Psicologia. Como instituição de apoio ao profissional, neste mesmo ano houve um movimento no interior do Sistema Conselhos para propor revisão do Código de 1979.

Conforme explana o texto da Exposição de Motivos do Código de Ética Profissional do Psicólogo, a proposta era desenvolver um instrumento menos corporativo e que efetivamente se preocupasse com as transformações sociais, considerando as necessidades e anseios da categoria, porém, sem perder de vista os interesses da população.

Assim, quando completou 25 anos de regulamentação da Psicologia no Brasil, o CFP aprovou o terceiro Código de Ética Profissional do Psicólogo - Resolução CFP $n^{\circ}$ 002/87, de 15 de agosto de 1987. No percurso de elaboração deste Código, muitas pesquisas foram realizadas com a participação de psicólogos de todos os Conselhos Regionais de Psicologia e grupos de profissionais de diferentes áreas 
foram consultados, efeitos do contexto histórico de redemocratização em processo no país (1987-1988).

Em documento emitido e encaminhado pelo Conselho Federal de Psicologia aos Regionais - Ofício s/n ${ }^{\circ}$ CFP de 20 de julho de 1986 -, há um histórico dos eventos que levaram à elaboração de um modelo normativo e reflexivo, o qual lê-se em parte:

Ouvindo as necessidades e dificuldades dos Conselhos Regionais através das Comissões de Ética, o CFP encampou a iniciativa de reformulação do código de Ética. Formaram-se grupos de trabalho que vêm se reunindo desde 1984, numa tentativa de operacionalizar a proposta. Em reuniões junto ao Federal, os Presidentes das Comissões de Ética dos Regionais concordaram quanto à necessidade de revisar o atual código de Ética. Também ficou vista a necessidade desta revisão ser baseada numa ampla consulta à classe. As discussões e reflexões das Comissões em reuniões conjuntas, o contato com a categoria, o contato com filósofos e profissionais de outras áreas para esta reformulação, fizeram surgir sugestões que levaram ao aprofundamento da questão Ética. Neste contexto surgem propostas que pretendem um código de Ética profissional bem geral, bem como aquelas que indicam como melhor forma a que procura explicitar cada situação profissional possível de acontecer e a atitude a ser tomada em cada caso. A partir de outubro do mesmo ano houve nova reunião dos presidentes das Comissões de Ética em Brasília. Nesta oportunidade os Regionais colocaram como estavam seus trabalhos de consulta aos psicólogos.

Na cidade do Rio de Janeiro, o CRP-05 apresentou aos profissionais um questionário com perguntas sobre o Código de Ética e promoveu debates com jovens estudantes do último ano do curso de graduação em Psicologia, bem como com professores de Ética em diversas Universidades. Nas discussões com profissionais, privilegiou a área de Psicologia Organizacional que vinha firmando convênios com os Serviços de Psicologia Aplicada (SPA), organizando debates com estudantes em estágio básico.

A participação do CRP-08 se deu pela distribuição de um formulário para a categoria. Quanto ao CRP-07, este preferiu realizar encontros com os profissionais no modelo de seminários para discutir o tema. $O$ CRP-04, após inexpressiva participação por meio de formulários, organizou mesas-redondas e debates com outros profissionais para mobilizar a categoria. O CRP-03 realizou consulta interna, nas próprias Comissões.

Quanto ao CRP-02, após debates com a categoria, emitiu nota informando que a maioria dos profissionais desconhecia o seu Código 
de Ética, entendendo que este instrumento era pouco empregado para embasar a conduta profissional. Embora admitisse a necessidade de um código que refletisse a práxis do psicólogo, declarou que a categoria não demonstrou interesse em participar da mudança do Código.

O CRP-01 também foi outro Regional que desenvolveu atividades junto à categoria, inovando com a organização de Grupos de Trabalho (GT) para discutir o modelo de Código de Ética, enviando modelos para que os profissionais tivessem a oportunidade de opinarem.

Em São Paulo, o CRP-06, além de promover reuniões com professores de Ética, o Regional tomou a iniciativa de elaborar um questionário, que foi encartado na edição do Jornal PSI de julho de 1984, para que os psicólogos de São Paulo pudessem contribuir para a ampliação do CEPP. Transcritas, a seguir, as quatro primeiras questões referentes à primeira página do questionário:

1. Qual deve ser a finalidade de um Código de Ética:

a. Preferencialmente normalizador? Por quê?

b. Preferencialmente reflexivo? Por quê?

c. Preferencialmente ? Por quê?

2. A seu ver, o atual Código de Ética cumpre essa finalidade? Por quê?

3. A quem deve servir o Código de Ética?

4. A quem deve servir a Psicologia?

O material analisado foi apresentado em maio de 1985 para o CFP e demais CRPs em reunião realizada para fins de estabelecer diretrizes básicas que deveriam nortear as propostas para a feitura do novo Código. Concluiu-se por três diretrizes, que seriam: (1) prioridade para os interesses da comunidade; (2) ascendência da ação orientadora em relação à punitiva; (3) estabelecer uma definição entre questões éticas e questões técnicas para dirimir essa falsa dicotomia (Conselho Regional de Psicologia 06, 1994).

O Código de 1987, Resolução CFP n 002/87, conforme explicita seu texto introdutório, procurou agregar princípios gerais e básicos com normas mais detalhadas que pudessem fundamentar e operacionalizar as situações profissionais, sendo, ao mesmo tempo, um convite à "dinamicidade criadora" e uma proposta de caminhos como soluções de problemas. Também buscou, pela primeira vez, oferecer uma conceituação do que o CFP entendia por ética (Conselho Federal de Psicologia [CFP], 1987):

Éthos, segundo Aristóteles, expressa um modo-de-ser, uma atitude psíquica, aquilo que o homem traz dentro de si na sua relação consigo, com o outro e com o mundo. Indica as disposições do ser humano perante a vida. Ser ético é muito 
mais do que um problema de costumes, de normas práticas. Supõe a boa conduta das ações, a felicidade pela ação feita e o prêmio ou a beatitude da alegria da auto-aprovação diante do bem-feito, no dizer de Aristóteles.

Neste sentido, o Código de 1987 conceituava Ética enquanto Filosofia Moral ou ética filosófica, que recorre à reflexão e à compreensão das singularidades, que permite o exercício da criatividade, da liberdade e da espontaneidade. Portanto, uma ética capaz de fazer o psicólogo ver o cliente como um ser de relação no mundo.

Por sua vez, entendendo ética também como Ciência dos Costumes, o Código dizia respeito aos deveres sociais do homem e de suas obrigações na comunidade, lembrando que o ser humano não pode viver ao sabor de suas paixões e que a vida não é apenas deixar-se viver. Ao indivíduo, é requerida uma conduta moral para viver em sociedade ou em grupo, respeitando certas regras ou leis e tendo por base a disciplina, a adaptação à vida grupal e a autonomia da vontade. O Código ainda salientava que o agir ético vai além do pensar bem e honestamente, mas exige do profissional estar consciente de suas ações. Assim, ao mesmo tempo em que deveria expor normas explícitas, um Código de Ética não poderia oferecer soluções pré-fabricadas, entendendo que caberia a cada indivíduo agir eticamente. Neste caso, o psicólogo deveria, antes de cumprir as normas do Código, ser ético. Desta feita, o Código se propunha a servir como um mapa, assinalando os principais caminhos de onde decorre a vida, como um convite à reflexão e à descoberta de valores que deveriam guiar a ação/prática profissional. I gualmente, o Código de Ética deveria também estar sujeito às leis da mudança, aberto a reflexões que o atualizassem continuamente.

Nesta perspectiva, a concepção de ética proposta pelo Conselho Federal de Psicologia referia-se à ética enquanto prática de si, portanto, uma ética que não equivale à moral. Trata-se de uma ética que tem compromisso com a sociedade, com o usuário do serviço de Psicologia e com o próprio psicólogo.

Após a extensa Exposições de Motivos, o CEPP de 1987 exibia sete Princípios Fundamentais e um total de 50 artigos e alíneas dispostos em 10 (dez) capítulos: das responsabilidades gerais do psicólogo; das responsabilidades e relações com as instituições empregadoras; das relações com outros profissionais ou psicólogos; das relações com a categoria; das relações com a justiça; do sigilo profissional; das comunicações científicas e da divulgação ao público; da publicidade profissional; dos honorários profissionais; da observância, aplicação e cumprimento do código de ética.

Apesar de bastante pormenorizado, o CEPP de 1987 recebeu críticas daqueles que tinham predileção pelo anterior, por considerá-lo mais claro e incisivo, enquanto outros salientavam o caráter corporativista 
e economicista que ainda persistia no Código que entrara em vigor. Outros, mais otimistas, ressaltaram que as transformações no Código colocaram o psicólogo como responsável pelo desenvolvimento de uma análise crítica da realidade política e social, assim como da própria Psicologia como ciência e profissão compromissada com o social (Vasconcelos, Masson, Menezes, Vasconcelos \& Ferreira, 2004). Algumas dessas críticas repercutiram diretamente no Código de 1987, que sofreu, anos mais tarde, duas alterações: uma em 1990, com a Resolução CFP N ${ }^{\circ} 006 \mathrm{~A} / 90$, que refogava o Art. $5^{\circ}$ e seus parágrafos, e outra em 1995, com a Resolução CFP Nº 002/95, que dispunha sobre a prestação de serviços psicológicos por telefone, incluindo a alínea 'o' ao Art. $2^{\circ}$, vetando esse tipo de atividade.

CONSIDERANDO análise efetivada pela Câmara de Orientação e Fiscalização sobre anúncios publicados em jornais relativos a serviços tais como Tele-Ajuda, Tele-Aconselhamento e similares; (...)

RESOLVE:

Art. $1^{\circ}$ - Incluir a alínea 'o' no Art. 02 do Código de Ética Profissional do Psicólogo, Resolução CFP 002/87 de 15 de agosto de 1987 com a seguinte redação:

Art. $2^{\circ}$ - Ao Psicólogo é vedado:

0) prestar serviços ou mesmo vincular seu título de Psicólogo a serviços de atendimento psicológico via telefônica (Conselho Federal de Psicologia [CFP], 1995).

Como parte desse intenso movimento de transformação no Sistema Conselhos, com a elaboração e instituição do novo Código de Ética, o Código de Processamento Disciplinar (CPD) também foi reformulado, passando a vigorar a Resolução CFP n 005/1988.

No período que entrou em vigor o novo CEPP, ideias e recomendações originais advieram no Sistema Conselhos, dentre elas a proposta para tornar a eleição para o Plenário do CFP direta, a partir da candidatura de uma chapa de caráter nacional, fato que se efetivou em 1989, com o estabelecimento de um projeto de democratização interna e redução da visão corporativista que atravessava a profissão. Assim, naquele ano, mais de 65 mil psicólogos escolheram, pela primeira vez, seus representantes federais por voto direto (Conselho Federal de Psicologia [CFP], 2004). Também foi em 1989 que ocorreu o Congresso Nacional Unificado dos Psicólogos, um dispositivo que visava iniciar um diálogo entre CFP, sindicato e categoria a partir do compromisso assumido pelo próprio Conselho Federal em buscar meios de diluir a concepção corporativista. Temas deliberados neste Congresso foram encampados pela Gestão do VII Plenário (1989 a 1992). Este fato foi considerado como um evento que fortaleceu a democratização no 
interior do Conselho Federal, dando início a uma série de movimentos e articulações, como a realização do Encontro Geral de Plenárias, que ocorreu em 1991, a fim de dar continuidade às discussões iniciadas anteriormente. Uma das propostas desse evento foi a realização do Congresso Constituinte da Psicologia. Esta proposta gerou, durante três anos, discussões acerca das aspirações da categoria e necessidades da sociedade, do exercício e formação profissional, da importância social do trabalho, proporcionando, no ano de 1994, a efetivação do Processo Constituinte "Repensando a Psicologia" (CFP, 2004, p.11).

Foi um marco histórico para a Psicologia, porque esta foi a primeira vez, desde que a Psicologia havia sido criada, no Brasil, que, a partir de proposições próprias, os psicólogos indicaram o rumo que a Psicologia deveria tomar no país, como ciência e profissão, e a forma de organização dessa área.

O evento ficou conhecido como o I Congresso Nacional de Psicologia (CNP, Campos do Jordão, 1994). Sua implementação visava transformar o papel, o funcionamento e a ação dos Conselhos de Psicologia rumo a uma sociedade democrática, a partir de um amplo processo de debates. Criado para ser a instância máxima de deliberação na estrutura do Sistema Conselhos, o CNP define e aprova as diretrizes básicas para a ação política dos Conselhos de Psicologia a cada três anos, quando ocorre novo encontro. Por ocasião do CNP, espera-se que as chapas que pretendem concorrer às eleições para a direção do CFP e CRPs sejam inscritas.

\section{Quarto código de ética profissional do psicólogo}

Em 1997, já era possível identificar um movimento de intenção para reformular o CEPP - que começou com o I Fórum Nacional de Ética realizado em 1997, em Brasília -, reflexo da necessidade que a categoria tinha em sintonizar-se com o "contexto institucional-legal do país, marcadamente a partir da promulgação da denominada Constituição Cidadã, em 1988" (Conselho Federal de Psicologia, 2005), com vistas a democratizar o acesso da população a um conhecimento científico bastante elitizado.

Neste rumo, o IV CNP, realizado em 2001, cujo tema foi Qualidade, Ética e Cidadania nos Serviços Profissionais: construindo o compromisso social da Psicologia, teve por objetivo, dentre outros, a discussão e reflexão sobre ética, responsabilidade jurídica e social do psicólogo-cidadão frente às novas tendências da sociedade, para fins de iniciar um processo democrático de reformulação do Código de Ética Profissional (Jornal PSI, 2004, janeiro/fevereiro). 
Concomitantemente às discussões sobre a reformulação do Código de Ética houve, no ano de 2001, a revogação do Código de Processamento Disciplinar, Resolução CFP nº 005/1988. Em seu lugar foi instituída a Resolução CFP $n^{\circ}$ 006/2001 e com ela, a principal alteração estabelecida que trouxe repercussões importantes na instrução processual: a possibilidade da interrupção do prazo prescricional para apuração de eventuais infrações ao CEPP.

Conforme preceituava a Resolução CFP $n^{\circ}$ 005/88 (Conselho Federal de Psicologia [CFP], 1988), não havia possibilidade de interrupção do prazo prescricional, o que significa dizer que todo o Processo Disciplinar Ético, desde a denúncia (comunicação do fato ao CRP) até a manifestação final em última instância deveria perdurar cinco anos. Com a vigência da Resolução CFP $n^{\circ}$ 06/2001 (Conselho Federal de Psicologia [CFP], 2001), a interrupção da prescrição ficou prevista por ocasião de a Comissão de Ética receber a Representação, da citação do denunciado ou de decisão do Plenário, conforme estabelece o $\S 1^{\circ}$ do Art. 91. Certamente, com a interrupção da prescrição, o prazo prescricional recomeçaria a contar, evitando que muitos processos fossem arquivados sem o devido julgamento do mérito.

Com o CPD regulamentado, as discussões tomaram o curso para análise de sua aplicabilidade, assim como para a confecção do novo Código de Ética. Em 2003, por iniciativa do XII Plenário do Conselho Federal de Psicologia, o Sistema Conselhos promoveu o II Fórum Nacional de Ética em Brasília. Por meio de uma metodologia considerada democrática, a categoria profissional poderia participar de Fóruns Regionais de Ética (eventos preparatórios) para discussão acerca da revisão do Código de Ética Profissional do Psicólogo e oferecer propostas (teses). Para este II Fórum Nacional, os psicólogos participantes construíram proposições sobre as condutas profissionais, diretrizes de políticas do Sistema Conselhos, também voltando a atenção à redação e exatidão dos termos que viriam a ser utilizados no novo Código de Ética da categoria (Jornal PSI, 2003, setembro/outubro).

Como resultado dos Fóruns Regionais, 420 teses (propostas) foram acolhidas e encaminhadas pelos delegados representantes dos Conselhos Regionais para discussão no II Fórum Nacional de Ética. Algumas Resoluções do Conselho Federal de Psicologia foram assimiladas neste Fórum e incorporadas às discussões da revisão do CEPP, dentre as quais as que censuravam a prática de exclusão, tais como: a questão relativa ao tratamento da homossexualidade (Resolução CFP $n^{\circ}$ 01/99), a complacência com culturas discriminatórias (Resolução CFP n 18/2002). Outras que tratavam da qualidade da produção de documentos escritos, da realização de pesquisa com seres humanos e do atendimento psicoterapêutico pela Internet também foram consideradas. A intenção era firmar 0 
compromisso da categoria com movimentos sociais vinculados à questão da defesa dos direitos da sociedade (J ornal PSI, 2004).

Submetido, à época, à Assembleia das Políticas Administrativas e Financeiras (APAF) do Sistema Conselhos - instância deliberativa do Conselho Federal e Regionais de Psicologia estando subordinada às deliberações do Congresso Nacional da Psicologia -, o relatório final do II Fórum Nacional continha as propostas de ampliação e modernização do Código de Ética. Para este fim, a APAF optou pela criação de um Grupo de Trabalho (GT) que se encarregou de fazer a minuta do Código de Ética que deveria ser avaliado e aprovado pelos Plenários do Sistema Conselho, retornando, posteriormente, à APAF, quando seria entregue à categoria a versão final. As propostas de ações políticas que não se transformaram em artigos do Código de Ética puderam ser aproveitadas sob a forma de Resoluções do CFP (Jornal PSI, 2004).

Assim, o Código de Ética, Resolução CFP N 010/2005 foi aprovado, entrando em vigor na data em que se comemorava o dia do Psicólogo daquele mesmo ano. O documento consta de sete Princípios Fundamentais e 25 artigos, distribuídos em dois capítulos: das responsabilidades do psicólogo e das disposições gerais.

Conforme a Resolução CFP $n^{\circ}$ 010/2005 descreve no texto de Apresentação do documento, o Código "foi construído a partir de múltiplos espaços de discussão sobre a ética da profissão, suas responsabilidades e compromissos com a promoção da cidadania" (Conselho Federal de Psicologia [CFP], 2005, p.5). Viabilizando a participação dos psicólogos e da sociedade, sua intenção era "aproximar-se mais de um instrumento de reflexão do que de um conjunto de normas a serem seguidas pelo psicólogo" (CFP, 2005, p.5). A partir dessas considerações, o CFP - responsável pela construção democrática do CEPP - , manifestou, ao final do texto, sua expectativa de que o Código "seja um instrumento capaz de delinear para a sociedade as responsabilidades e deveres do psicólogo, oferecer diretrizes para a sua formação e balizar os julgamentos das suas ações, contribuindo para o fortalecimento e ampliação do significado social da profissão" (CFP, 2005, p.5).

Comparado aos demais, este novo Código (atualmente em vigor) é bastante reduzido, tendo eliminado alguns artigos e alíneas e, por conseguinte, deixando de tratar alguns temas de forma mais específica e direta, para se tornar um instrumento com princípios mais gerais e amplos, com a finalidade de permitir a discussão e reflexão da profissão como um todo. De modo geral, esta foi a intenção do Código: deixar de ser um instrumento fundamentalmente prescritivo para ser um Código que permita o exercício do pensamento, possibilitando a ética se fazer presente, enquanto associada à prática profissional. No entanto, será que alcançou seu intento? 
Patrícia Garcia, presidente da Comissão de Ética do CRP-SP (Gestão 2007-2010), em entrevista para o J ornal PSI do CRP-SP, explicou que a proposta do Código é trazer diretrizes de práticas passíveis de ocorrer em diversos contextos e não mais em situações específicas. Para a conselheira, tal estrutura permite que o psicólogo possa exercer uma reflexão sobre os princípios expostos no Código e articulá-los com sua prática, tornando-o "um instrumento de diálogo do profissional com suas ações, independentemente do seu campo de atuação" (Jornal PSI, 2005, outubro/dezembro, n.p.).

Interrogada pelo Jornal PSI (2009) sobre a possibilidade de que o Código de Ética seja suficiente para que o psicólogo possa atuar de forma ética na sua profissão, outra psicóloga, Patrícia M. G. Cintra Mortara, professora de Ética Profissional no curso de Psicologia da PUC-SP e integrante da Comissão de Ética do CRP-SP naquele período, respondeu que "o Código não é um oráculo, com respostas prontas e fechadas para tudo. Se assim fosse, isto é, se tudo se resumisse a seguir preceitos e normas [...], não se poderia falar em análise, reflexão [...] em ação ética" (Jornal PSI, abril/maio 2009, n.p). Trata-se de um instrumento historicamente construído, fruto de uma visão de Psicologia edificada ao longo de décadas e consubstanciada em um momento específico, que deve servir como parâmetro para que o psicólogo se posicione diante de situaçõesproblemas de forma reflexiva e crítica, tendo as normas como referência. Realizando uma análise das implicações de sua ação juntamente com uma reflexão sobre as normas, o psicólogo terá meios de melhor decidir.

De acordo com a Resolução CFP Nº10/2005:

Um Código de Ética profissional, ao estabelecer padrões esperados quanto às práticas referendadas pela respectiva categoria profissional e pela sociedade, procura fomentar a auto-reflexão exigida de cada indivíduo acerca da sua práxis, de modo a responsabilizá-lo, pessoal e coletivamente, por ações e suas consequências no exercício profissional. A missão primordial de um código de ética profissional não é de normatizar a natureza técnica do trabalho, e, sim, a de assegurar, dentro de valores relevantes para a sociedade e para as práticas desenvolvidas, um padrão de conduta que fortaleça o reconhecimento social daquela categoria (CFP, 2005, p.5).

Opiniões e críticas divergentes foram endereçadas ao Código, especialmente no que se refere ao caráter generalizante: para uns, é promissor "uma espécie de guia genérico de conduta profissional que apontará para realidades" (Jornal PSI, 2004, n.p); para outros, o Código deixou de assegurar ao profissional a sustentação que precisa 
em sua atuação. "Não sei se visando privilegiar a iniciativa do profissional, ou quem sabe seu livre arbítrio, deixou-se de lado justamente o que se espera de um Código de Ética, ou seja, um norte, uma orientação" (Brito, 2007, n.p). Neste caso, Brito (2007) também chamou a atenção para a dificuldade que os profissionais teriam para encontrar no Código de Ética, quando necessário, os artigos que se referem às situações-problemas ou dilemas deparados no cotidiano da profissão.

Nesta linha de raciocínio desenvolvida por Brito (2007), André Martins, em entrevista ao Jornal do CRP-RJ (2007), alertou que, ao tentar formalizar a ética em um Código - cujo caráter é fundamentalmente moralista -, corre-se o risco de transformá-lo em um instrumento que deixa de contemplar uma série de questões (ou passa a tratá-las de forma ambígua), desamparando os profissionais que ficam sem ter como lidar com as situações-problemas não enquadradas naquele instrumento.

Elisa Zaneratto Rosa, ao ser entrevistada pelo Jornal PSI (2004), a psicóloga Conselheira-Presidente da Comissão de Ética do CRP-SP (Gestão 2004-2007) e coordenadora do Grupo de Trabalho organizador do II Fórum Regional de Ética emitiu opinião de que os Códigos anteriores, aprovados na década de 1970, não contemplavam todas as possibilidades de atuação profissional, pois eram eminentemente voltados à área clínica. O Código atual, na opinião dela, é mais abrangente, perdendo "o eco predominantemente clínico" (Jornal PSI, 2004, n.p) para assumir compromissos perante a sociedade, viabilizando a sanção do profissional, por exemplo, nos casos de práticas de exclusão e discriminação.

Aluízio Brito, responsável pela coordenação dos trabalhos de construção do novo Código, também em entrevista para o Jornal PSI (2004), comentou que acredita que este Código esteja em sincronia com as legislações vigentes (Código de Defesa do Consumidor, o Código Brasileiro de Trânsito, o Estatuto do Idoso e o Estatuto da Criança e do Adolescente), incorporando vários de seus princípios. Para o referido psicólogo, a atenção voltou-se à responsabilidade e às relações com a Justiça, entendendo que o novo Código de Ética vem assegurar uma relação transparente dos psicólogos que trabalham com avaliação psicológica no campo da Justiça e no Poder Judiciário.

Brito (2007) é de opinião diversa. A autora, em palestra no CRP do Rio de Janeiro, promoveu uma série de observações e críticas ao novo Código, entendendo que o documento que entrou em vigor em 1987 fornecia, sob alguns aspectos, mais suporte ao profissional que atua junto ao poder judiciário. Para ilustrar, a autora citou alguns exemplos: tomando o Artigo $1^{\circ}$ do Código de Ética de 2005 como referência, questionou o sentido da expressão "a quem de direito" disposta nas alíneas "f", "g", " $h$ ". Alegou que muitos profissionais têm 
dúvidas quanto à definição de "quem" teria direito às informações dos serviços psicológicos. No Código de 1987, o texto define que se trata da "pessoa atendida" quem tem o direito a tais informações, prevendo a possibilidade de, apenas na "incapacidade dessa", o psicólogo vir a prestar informações "a quem de direito". Logo, Brito (2007) constata que, no atual CEPP, esse entendimento foi generalizado, abrindo margem para interpretações diversas.

Nesse sentido, é possível recordar palestra de um promotor, em evento promovido pelo Ministério Público do Estado do Rio de Janeiro em 03 de julho de 2009, cujo tema em debate era o testemunho de crianças como vítima de violência sexual. Em sua fala, o promotor relatou que a expressão "a quem de direito" refere-se ao juiz, devendo, portanto, o profissional psicólogo reportar-se ao mesmo para fins de fornecer, informar e orientar acerca de conteúdo relativo à prestação de serviço psicológico, conforme expresso na Resolução CFP n ${ }^{\circ} 010 / 2005$.

Nesses casos, pode ocorrer do psicólogo que atua no âmbito judiciário se ver, muitas vezes, compelido a atender à demanda judicial e a prestar as informações sem conseguir dispor de argumentos para fundamentar opinião ou interpretação contrária.

Brito (2007) ressaltou, em mais uma ilustração de caso, que alguns psicólogos que atuam no judiciário queixam-se em relação à compreensão do Art. 11: quando requisitado a depor em juízo, o psicólogo poderá prestar informações, considerando o previsto neste Código. Não está claro no CEPP em que condições o psicólogo é requisitado a depor:

$\mathrm{Na}$ qualidade de quê? Na qualidade de perito, na qualidade de testemunha $[\ldots]$ ? O que vem acontecendo são situações em que psicólogos do Tribunal que atuaram em determinados casos, realizaram uma avaliação psicológica, e às vezes, anos, meses depois, são requisitados, enquanto testemunha, para depor em outros processos correlatos. E aí, eu acho que o código desampara, em muito, esses profissionais (Brito, 2007, n.p).

Outro aspecto a se considerar neste artigo é a expressão "poderá prestar informações". À semelhança das considerações anteriores, entende-se que este artigo também não deixa claro em que circunstâncias o psicólogo poderá ou não prestar informações, tampouco sustenta que tipo de informação pode ou não ser comunicada.

$\mathrm{Na}$ apreciação da conselheira Patrícia Garcia, trata-se de uma inovação desta Resolução que o torna "orgânico; ou seja, considera a prática como um todo, sem divisões temáticas" (Jornal PSI, out/dez 2005), cujo interesse seria oferecer maior poder de deliberação ao 
psicólogo no exercício profissional. Com efeito, a conselheira entende que o novo Código exige do profissional uma leitura ampla e não fragmentada do instrumento.

A partir dessas considerações, entende-se que, embora seja fundamental que o psicólogo se utilize do Código como um aliado em suas reflexões, mantendo sua autonomia e poder de deliberação, é preciso encontrar neste instrumento, diretrizes operacionais que fundamentem uma tomada de decisão.

O fato de que o Código tornou-se amplo e generalista, a partir de uma proposta "de aproximar-se mais de um instrumento de reflexão do que de um conjunto de normas a serem seguidas pelo psicólogo" (CFP, 2005, Resolução CFP n 010/2005), tem gerado dúvidas nos profissionais, os quais encontram dificuldades na aplicação de artigos do Código com as demandas que Ihes são endereçadas no cotidiano do seu exercício profissional. $O$ instrumento apresenta-se, portanto, carente de objetividade em determinados artigos, permitindo a múltiplas interpretações.

Assim, diante de juízos divergentes quanto ao caráter generalista do Código de Ética Profissional do Psicólogo (CEPP), associado à dificuldade da categoria compreender e tornar esse dispositivo executável, defende-se a legitimidade da solicitação dos profissionais por maior objetividade ao Código de Ética e orientações acerca do que pode ou não ser feito, porquanto, de nada serve uma norma que não cumpra com seu papel norteador para com as atividades profissionais.

Por sua vez, a reivindicação de muitos psicólogos para que o Código de Ética vislumbre as especificidades de seu campo de atuação não deixa de ser um requerimento para o retorno do Código de Ética aos moldes do de 1987. Talvez, um sinal de que o Código em vigência, dito "democrático", não teve uma expressiva participação da categoria como se profere.

Resultado dessa demanda pela especialização do Código de Ética tem sido a produção de outras normativas pelo CFP que fragmentam, complementam e especializam o Código, via Resoluções e Referências Técnicas outras, para normatizar áreas de atuação específicas. Um movimento oponível à proposta do próprio CFP de manter um dispositivo de reflexão unificador das diversas práticas psicológicas, independentemente dos lugares e da forma como se deem.

A partir disso, entende-se que o atual Código de Ética, primando pela abrangência e promoção da autonomia e reflexão do profissional, vai de encontro com a prática cada vez mais especializada do profissional, que não se vê contemplada nestes princípios norteadores. Dessa forma, o Código desponta como um indicador, não apenas de críticas divergentes, mas, também, de um problema grave: a constatação da dificuldade que o psicólogo encontra para 
empregar o Código no exercício de sua profissão, e igualmente promover uma reflexão sobre sua práxis.

Cabe salientar que, embora desejada, a espera por normas firmes e confiáveis a abrigar às práticas profissionais é tarefa "em vão" (Bauman, 2003, p.28), pois não há autoridade, não há normas ou códigos poderosos o suficiente para oferecer ao psicólogo o grau de segurança que busca. Tampouco há respostas prontas, pois não basta um Código de Ética Profissional para garantir a conduta moral. Afinal, "precisamos aprender a viver sem essas garantias e conscientes de que nunca se oferecerão essas garantias" (Bauman, 2003, p.16).

\section{Algumas considerações a título de conclusão}

Obedecer ao Código de Ética Profissional do Psicólogo (CEPP) tem sido, para muitos psicólogos, medida apaziguadora, em que o cumprimento do Código se confunde com agir eticamente.

Neste caso, se o profissional estabelece uma relação de dependência acrítica com seu código de conduta, o que ocorre é uma espécie de ética da tutela. Entende-se que a razão para buscar tutela nos ditames do Código deve-se ao sentimento de insegurança e angústia que vem sobrepujando os sujeitos pós-modernos pelo fato de terem que - guiados por suas reflexões e incertezas - fazer escolhas livremente e serem, por estas, responsáveis.

Em uma sociedade individualizada, como explica Bauman (2011, p.24), os sujeitos vivem em um "estado de incerteza aguda", de tal forma que as "escolhas obrigatórias estão cheias de sonhos de libertação das responsabilidades" (Bauman, 2011, p.53), com isso, muitas pessoas estariam dispostas a renunciar formas de liberdade em nome da segurança. Tal lógica estaria, no mundo contemporâneo, disseminada em todos os âmbitos da vida, incluindo a profissional, quando o psicólogo, por exemplo, estaria disposto a abrir mão da liberdade de pensar, de criar, inovar em seu fazer para manter-se atrelado à obediência à técnica, ao cumprimento estrito do Código.

Seguramente, é mais fácil suportar a responsabilidade dos atos e escolhas praticados se estes estiverem apoiados em normas, leis, diretrizes, postas por uma autoridade da qual se deve obediência, à semelhança do Conselho Federal de Psicologia. Todavia, não há código de comportamento moral que se possa "aprender, memorizar e desenvolver para escapar de situações sem bom resultado (...) na esteira das decisões tomadas ou realizadas. A realidade humana é confusa e ambígua, e também as decisões morais" (Bauman, 2003, p.41).

Assim, salienta-se que o Código de Ética atual é generalista, com caráter referencial apenas, de modo que as particularidades de cada situação exigem reflexão ampla que devem considerar, além do 
Código de Ética, os valores e princípios nutridos pelo psicólogo ao longo de sua formação pessoal e profissional. Certamente, tais princípios pessoais devem ser respeitados e não rejeitados em nome de uma neutralidade infactível. Contudo, respeitar esses valores não é o mesmo que o psicólogo agir fundamentado apenas sobre eles, o que levaria à banalização e ao senso-comum (Reis, Rodrigues \& Melo, 2010).

Todos esses investimentos feitos pelo Sistema Conselho, desde a confecção e as sucessivas reformulações das Resoluções que instituem o Código de Ética Profissional, incluindo as Resoluções destinadas à instrução processual e ao julgamento de infrações do Código de Ética, como o novo Código de Processamento Disciplinar (CPD), Resolução CFP $n^{\circ}$ 006/2007, são expressões de um tempo, reflexos inspiradores de uma atitude renovada em relação à Psicologia, construções que apontam para uma trajetória de reconhecimento da profissão no campo social, bem como da necessidade de firmar um compromisso ético-político da categoria para com a sociedade da qual é prestadora de serviços.

Se pelos princípios do Código almeja-se certo nível de excelência profissional, é de se esperar que o psicólogo, sob a pressão dessa exigência, também reivindique ser bem representado pelos Conselhos (Regional e Federal), na intenção de obter referências mais precisas para subsidiar a atuação profissional em situações específicas.

Neste caso, fica a sugestão de que é preciso avançar para além da aplicabilidade do Código e pensar a formação do profissional psicólogo e como se dão as discussões sobre o Código de Ética nas instituições formadoras para, futuramente, haver meios efetivos de que a categoria tenha uma participação na construção de suas normativas. Mas isso já é tema para outra história...

\section{Referências}

Aguiar, A. R. (1984). Direito, poder e opressão (2a. ed.). São Paulo: Ed. Alfa-Omega.

Bauman, Z. (2003). Ética Pós Moderna. (2a. ed.). Rio de Janeiro: J. Zahar Ed.

Bauman, Z. (2011). Ética é possível num mundo de consumidores? (2a. ed.). Rio de Janeiro: J. Zahar Ed.

Benavides, M. F. B., \& Antón, E. (1987). Ética profissional: deontologia da profissão de psicólogo. Brasília, DF: Thesaurus.

Benjamin, W. (1989). Charles Baudelaire: um lírico no auge do capitalismo, Obras Escolhidas III. São Paulo, SP: Brasiliense.

Bock, A. (2008). Política do Sistema Conselhos de Psicologia para as Comissões de Ética. In Código de Processamento Disciplinar 
Comentado. Profissão Psicólogo, legislação e resoluções para a prática profissional, XIII Plenário. Brasília, DF: CFP.

Brito, L. M. T. (2007) Avaliação Psicológica no Âmbito Jurídico e o Agir Ético. Recuperado de:

http://www.crprj.org.br/noticias/quarteticas/Leila_Torraca. pdf.

Conselho Regional de Psicologia 06 (1994). Uma profissão chamada

Psicologia (CRP-06, 20 anos). São Paulo, SP: CRP-06.

Conselho Federal de Psicologia (1975). Resolução CFP Nº 010/1975, Código de Ética Profissional do Psicólogo, I Plenário. Brasília, DF: CFP.

Conselho Federal de Psicologia. (1976). Resolução CFP Nº 014/1976, Código de Processamento Disciplinar. Brasília, DF: CFP.

Conselho Federal de Psicologia. (1978). Resolução CFP Nº 001/1978, II Plenário, Comissão de Orientação e Fiscalização. Brasília, DF: CFP.

Conselho Federal de Psicologia.(1979). Resolução CFP n 029/79.

Código de Ética Profissional do Psicólogo, III Plenário, Brasília, DF: CFP.

Conselho Federal de Psicologia. (1982). Resolução CFP N 015/1982.

Código de Processamento Disciplinar. Brasília, DF: CFP.

Conselho Federal de Psicologia. (1983). Resolução CFP N 009/1983. Código de Processamento Disciplinar. Brasília, DF: CFP.

Conselho Federal de Psicologia. (1987). Resolução CFP $N^{\circ}$ 002/87. Código de Ética Profissional do Psicólogo, VI Plenário, Brasília, DF: CFP.

Conselho Federal de Psicologia. (1988). Resolução CFP № 005/88. Código de Processamento Disciplinar. Brasília, DF: CFP.

Conselho Federal de Psicologia. (1995). Resolução CFP Nº 002/95, dispõe sobre a prestação de serviços psicológicos por telefone. Brasília, DF: CFP.

Conselho Federal de Psicologia. (2001). Resolução CFP n 006/2001. Código de Processamento Disciplinar. Brasília, DF: CFP.

Conselho Federal de Psicologia. (2004). Sistema Conselhos de Psicologia: 30 anos de história. Edição Comemorativa. XII Plenário. Brasília, DF: CFP.

Conselho Federal de Psicologia. (2005). Resolução CFP n 010/2005. Código de Ética Profissional do Psicólogo, XIII Plenário. Brasília, DF: CFP.

Conselho Federal de Psicologia. (2007). Resolução CFP n 006/2007. Código de Processamento Disciplinar. Brasília, DF: CFP.

Drawin, C.R. (1985). Ética e Psicologia: por uma demarcação filosófica. Psicologia Ciência e Profissão, 5(2), 14-17.

Jornal do CRP-RJ (2007). A ética como prática, ano 4, (14).

Jornal PSI CRP-SP (2003, setembro/outubro). Documentos escritos: uma boa relação evita denúncias no CRP-SP, (137). Recuperado de: 
http:// www.crpsp.org.br/portal/comunicacao/jornal_crp/137/fra $\mathrm{mes} / \mathrm{fr}$ questoes_eticas.aspx.

Jornal PSI CRP-SP. (2004, janeiro/fevereiro). Novo Código de Ética reafirma compromisso social do psicólogo, (139). Recuperado de:

http:// www.crpsp.org.br/portal/comunicacao/jornal_crp/139/fra mes/fr_questoes_eticas.aspx.

Jornal PSI C̄RP-SP.(2005, outubro/dezembro). Novo código para novos tempos, (145). Recuperado de: http://www.crpsp.org.br/portal/comunicacao/jornal_crp/145/fra $\mathrm{mes} / \mathrm{fr}$ questoes_eticas.aspx.

Jornal PSI CRP-SP.(2009, abril/maio). Ética, competência e política, (160). Recuperado de: http:// www.crpsp.org.br/portal/comunicacao/jornal_crp/160/fra mes/fr_questoes_eticas.aspx.

Matter, M.D.S.B. (n.d.) Entre a história e a ficção: a escrita de um novo olhar em seara de vento e levantando do chão (UFRJ). Recuperado de: http://www. artistasgauchos.com/conexao/01/michele. pdf.

Mello, S.L. (1983). Psicologia e Profissão em São Paulo. São Paulo, SP: Ática.

Oliveira, M.V. (2005). Referência ética para uma psicologia brasileira. Psicologia ciência e profissão, Diálogos, (2), 6-11.

Pegoraro, O. (2005). Introdução à ética contemporânea. Rio de Janeiro, RJ: UAPÊ.

Pereira, R.C. (1991). O código de ética e a ética do código: algumas considerações jurídicas. Psicologia Ciência e Profissão, 11(1-4), 32-35.

Reis, D.K, Rodrigues, A., \& Melo, C.M. (2010). A práxis do psicólogo face ao código de ética profissional. Revista científica eletrônica de Psicologia 8(14). Recuperado de: http: //www.revista.inf.br/psicologia/pages/artigos/ART08ANOVIII-EDIC14-MAIO2010.pdf.

Romaro, R.A. (2008). Ética na Psicologia. Petrópolis, RJ: Vozes.

Vasconcelos, A.M., Masson, F., Menezes, J.S.B., Vasconcelos, R.E., \& Ferreira, S.T. (2004). Profissões de saúde, ética profissional e seguridade social. In M.I.S. Bravo, A.M. Vasconcelos, A. S. Gama \& G. L. Monnerat (Orgs.) Saúde e Serviço Social (pp.4876). São Paulo, SP: Cortez; Rio de Janeiro, RJ: UERJ .

Velloso, E.D. (1980). A reformulação do código de ética dos psicólogos. In: Arquivos Brasileiros de Psicologia, 32(3), 147158.

Weil, P. (1967). Manual de Psicologia Aplicada (2a. ed.). São Paulo, SP: I tatiaia.

\section{Endereço para correspondência}




\section{Marcia Ferreira Amendola}

Hospital Universitário Pedro Ernesto

Avenida 28 de setembro, 77, Vila Isabel, CEP 20551-030, Rio de Janeiro - RJ, Brasil Endereço eletrônico: psi.amendola@gmail.com

Recebido em: 28/02/2014

Reformulado em: 22/05/2014

Aceito para publicação em: 09/06/2014

\section{Notas}

* Psicóloga da UERJ, Mestre e Doutora em Psicologia Social pela UERJ 